\title{
Committed to Sustainability in Daily Management
}

\author{
Anthony Kong1, Ming Kwan 2*, David Liu² \\ ${ }^{1}$ Department of Communication Design and Digital Media at Hong Kong Design Institute, Hong Kong, China \\ ${ }^{2}$ Faculty of Hospitality and Tourism Management, Macau University of Science and Technology, Macau, China \\ Email: *mwkwan@must.edu.mo
}

How to cite this paper: Kong, A., Kwan, M. and Liu, D. (2019) Committed to Sustainability in Daily Management. Open Journal of Business and Management, 7, 480491.

https://doi.org/10.4236/ojbm.2019.72032

Received: February 3, 2019

Accepted: March 9, 2019

Published: March 12, 2019

Copyright () 2019 by author(s) and Scientific Research Publishing Inc. This work is licensed under the Creative Commons Attribution International License (CC BY 4.0).

http://creativecommons.org/licenses/by/4.0/

\section{cc) (7) Open Access}

\begin{abstract}
Using the environmental protection daily measures in Park Island, Hong Kong as a case study, this research investigates various daily green measures that have been adopted in a private residential estate and explores how those measures has demonstrated outstanding green management in estate that raise the environmental protection awareness for residents. Design/Methodology/Approach: This paper identifies environmental protection measures adopted in estate management to raise environmental awareness for all of the residents. The objectives of environmental protection measures aimed at demonstrating the green management in estate and how to educate and encourage residents to support in daily green living. Authors conducted twenty-five in-depth semi-structured interviews with respondents so as to fully understand their views towards the green management in estate. Findings: Green facility management in estate, green measures in estate restaurant, green workshops and activities in clubhouses, and green events were perceived by all of the study respondents as interesting, interactive and influential, which raised environmental awareness, encourage residents to participate in environmental protection while they are living. Practical Implications: Based on the insights gained from respondents, positive influence are contributed by green facility management in estate, green measures in estate restaurant, clubhouse green workshops and activities, and clubhouse green events to demonstrate environmentally friendly estate management and raise the environmental protection awareness and encourage residents to take part in green practices. Estate management and residents should join hand in hand in daily environmental protection. Originality/Value: This paper urges for the importance of all residents and all estate management companies to engage in daily environmental protection for sustainable development. The aim of such an episode is to arouse all stakeholders of estate
\end{abstract}


to participate in daily environmental protection wholeheartedly for sustainable development.

\section{Keywords}

Estate Management, Environmental Protection, Sustainability

\section{Introduction}

As global warming begins to alert the awareness of the need for greater environmental conservation, energy efficiency, and better places to live and work becomes more prevalent [1]. Thus, environmental protection and conservation is paramount because when we protect the environment, we are not protecting some distinct, distant entity but ourselves. Similarly, the demand for green buildings and communities is expected to increase as well, for the reason that people today pay more attention to the healthiness and sustainability of the built environment. Therefore, ethics of conservation becomes the norm which is the necessary staple in any sustainable human endeavor [2]. Nowadays, residents focus on development to become more energy efficient and ecologically friendly. Consequently, sustainability has become a touchstone for many of the business sectors [1]. Nevertheless, it will bring increasing demand on energy supply; an increased burden on solid waste management, the pollution of water bodies and air has caused negative environmental effects. Owing to these effects, substantial uncertainty exists regarding the long-term implications of such negative environmental impacts, in particular, those relating to global climate change. This increasingly calls for environmental protection for all. With the continuous growth of the population along with the convergence of rising energy costs, climate change and other pressing environmental issues, all resident, management companies and governments should take the responsibilities for environmental protection. The impacts of climate change and the efforts to combat climate change touch on every part of our lives. The issue of climate change can only be sufficiently addressed with strong support from the government, the estate management companies and residents to engage in our daily green living.

\subsection{Park Island Background}

The setting for the present study was effective environmental measures adopted in daily estate management of Park Island, Hong Kong. Park Island named as "the leisure vacation island" is a private residential area situated in Ma Wan, which is located in the north-east part of Ma Wan. Park Island consists of over 5000 residential units with 35 blocks and 3 large clubhouses. In Park Island, over $40,000 \mathrm{sq} \cdot \mathrm{m}$ are covered with greenery with gardens and mini farms, taking up nearly $40 \%$ of the site area. Since vehicle restrictions are set in Ma Wan to limit the emissions, the project by and large is described as a "pollution-free green 
city" which promotes one-stop green building and management [3]. It is regarded as the first largest eco-friendly residential area which contains a large green space since planning [3]. The management is dedicated to implement and promote environmental protection concepts. Green concepts have applied in estate planning, design, resources purchasing, architectural work, gardening, daily management operation and management as well as estate activities and activities management. Both of the community and management of Park Island are striving to conserve and cherish the natural environment.

\subsection{Definitions of Terms}

- Pro-environmental behavior: Environmental behavior that changes the availability of materials or energy from the environment or alters the structure and dynamics of ecosystems or the biosphere in environmentally responsible way [4]. The factors that influence on pro-environmental behavior such as demographic factors, external factors such as institutional, economic, social and cultural; and internal factors such as motivation, pro-environmental knowledge, awareness, values, attitudes, emotion, locus of control, responsibilities and priorities) [5].

- Personal moral norms: An individual's sense of personal moral obligation to engage in pro-environmental behavior.

- Perceived behavioral difficulty: An individual's perceived amount of effort required to perform the behavior [5]. Perceived difficulty is related to how actual performance of the behaviour is perceived, perceived difficulty probably mainly reflects the affective or experiential component of attitude since the latter is, for example, related to the affections which are expected to be experienced during performance of the behaviour [6].

\section{Literature Review}

\subsection{Sustainable Development}

Over the years, concerns related to the environment have progressively escalated [7]. Sustainable development refers to a series of processes and practices, involving action, and focusing on the improvement of human life [8] [9] [10]. The analogies between sustainability and sustainable development advance towards an interrelationship understanding of a single system composed of human and environmental activities. Such understanding has a dual purpose: to satisfy human's needs and to support life-sustaining systems [11] [12]. Thus, sustainability encompasses systems and sustainable development looks towards human needs and their well-being. Human beings are not independent and isolated; they are part of a complex web of natural phenomena inserted in a single global system, which Moldan et al. [13] calls a myriad of relationships and interdependencies. Sustainable development is the key to achieve sustainability, which is considered the final long-term goal [14]. Sustainability consists of a goal or ultimate objective defined through scientific criteria, which measures and tracks the results 
generated by the use of sustainable development strategies. In order to achieve the sustainability of a given global system - to raise the level of sustainability quality - it is necessary to use the sustainable development process [15] [16]. Sustainability originally was used to describe development and resource consumption that can meet human's present needs while preserving the ability of the environment in sustaining people at present and in future. It involves considering environmental, economic, and social objectives when developing and implementing public policies and programs. It also involves considering the needs of the present as well as the needs of future generations. In other words, sustainable development rests on the harmony between the needs of stakeholders. Instead of being viewed as a destination, sustainable development is an ongoing process whereby behavior is adjusted in the social and economic development and improvement which emphasizes the qualitative improvement in people's well-being. In other words, the concept suggests the community continues to improve the quality of life of its inhabitants [17]. This long-term planning objective of a social-environmental system in balance calls for cooperative functioning among government, institutions, community groups as well as individuals; and the concept is continuously building up from the bottom up through community initiatives. For a business to operate towards sustainability, it should start with the belief that we are part of a larger system in business ecology and extends the willingness to examine the larger socio-economic system and how we impact it at the individual, community and organizational level, and eventually at the planetary level [18]. Hence, green value propositions will include benefits to the physical environment of buildings and facilities, benefits to the community, and improvements to the global environment [19]. It is beneficial to everyone for all businesses, all industry to make environmental sustainability as a management competency and an aspect of organizational excellence [20]. In fact, creating a green culture requires reinforcing people's positive behavior [20].

\subsection{Event}

The term event is used for describing different activities designed for different purposes. It can be public or private, commercial or charitable, celebratory or commemorative activities which bring people together to share an experience and produce a measurable outcome [21]. According to Berridge [22], activities are a unique moment in time and aside from everyday occurrences. It is an activity that gathers the target group in time and room, a meeting where a message is communicated and happening is created [23]. The event is all about peoplepeople coming together to create, operate, and participate in an experience [21]. The aims of environmental protection activities were to increase environmental awareness for the community. The objectives of environmental protection activities were showing the importance of community involvement, demonstrating environmentally friendly estate management and raising the environmental protection awareness for residents to live green. 


\subsection{Community Involvement}

Resident's involvement to live green should be a norm. We need to change their ways, their behaviors and their value to care about environmental protection and sustainability must become the social norm. Along with the term community, it is said that public participation is considered the centerpiece of the democratic process [24] which is very essential in community development. In other words, the development of a community requires the involvement and proactive participation of local community in identifying the strategies they wish to use to improve their quality of life [24]. In modern era, much of the policy depends on the knowledge and commitment of the people in approaching the objective of sustainable development. Since local community usually has much better knowledge about the assets and needs of the community, the development project which supported by the local community is more likely to be successful. In response to this, it is important to accomplish a high standard of education coupled with a willingness to make sacrifices at present in order to allow future generations to have choices in their own futures, equal to what we enjoy at present [17].

\section{Methodology and Research Methods}

Research on environmental measures in estate contributions has traditionally employed a variety of deductive processes, testing a plethora of hypotheses and pre-determined theories. Green promotion event researchers have typically approached the problem from a positivist perspective, utilizing quantitative research techniques such as surveys and questionnaires, and processing data with the help of statistical data analysis tools. While mostly deductive in nature, such research tools tend to measure a set of predetermined hypotheses, searching for answers to the "what" questions and not allowing for any additional factors to enter the researcher's process of reasoning [25]. Respondents in the activities context have been shown to demonstrate a multitude of contributions and it is very likely that their attitudes, behaviors, perceptions and experiences of the green promotion event differ. In order to gain a degree of emotional depth, which is not possible to achieve simply by analyzing quantitative data, a qualitative research approach has been chosen as a more appropriate research strategy. Qualitative research is considered to be "concerned with understanding things rather than with measuring them" [26], whereby the "subjectivity and the authenticity of human experience" allows the researcher to gain an insight into the different meanings, perceptions, feelings and attitudes of research subjects [27] [28].

Park Island was selected in this study because it was the first largest eco-friendly residential area in Hong Kong. The management of Park Island is dedicated, devoted and determined towards environmental protection and promotion which produced significant results such and being named the most energy-efficient residential estate by Friends of the Earth. The respondents were the 
residents in Park Island community. The sample group comprised fifteen female and ten male respondents, all aged 18 - 65. Their education levels were secondary [2], undergraduate [8] and postgraduate [10]. Due to limited resources available to the researchers made it impracticable to collect data from the entire research population. It is important that the respondents interviewed represent various age, marital status, number of children and career. In the current investigation interviewing would be discontinued once "saturation" was reached. At this point, no further insights would be forthcoming from the interviews [29]. This approach is consistent with the view that sample size is not the dominant concern, in qualitative research, with greater importance attached to richness and depth of data.

Data collection took place in the estate. The researcher undertook one-to-one in-depth semi-structured interviews lasting approximately 40 minutes at nearest restaurant. Respondents were given information about the purpose of the study and written consent was obtained. Topics and questions were designed to elicit responses regarding each participant's attitude, feelings, perceptions and pro-environmental protection behavior after attending environmental protection activities, exploring general themes proposed by the environmental behavior and personal moral obligation literature. The main interview questions are seeking the residents' views, thoughts and feelings on the green measures, strategies, events and activities in clubhouse operations and management.

Further questions and prompts were included to enquire their feelings, perceptions and attitudes after environmental protection activities, in order to identify any specific circumstances which may have contributed to a participant's pro-environmental behavior and personal moral obligation to engage environmental protection. The interviews were digitally recorded and summaries were written up. Responses were analyzed using manual coding, scanning the recordings and flagging emergent themes and common views [28]. Finally, the results were grouped into similar conceptual areas according to prevalent themes.

\section{Findings and Discussion}

Over the years, Park Island management has committed to implement various environmental protections measures to educate residents to adopt green living in every facet of their daily lives.

\subsection{Green Facility Management in Estate}

7-color recycle bins with instruction has been placed next to the service management office to educate the residents how to do recycling properly. Air jet hand dryers have been installed in the toilets of the clubhouse instead of using paper hand towels for residents to dry their hands after washing. Notice has been posted to remind residents to bring their own towels and self-contained water bottles for waste reduction. In addition, the estate implements effective green measures through daily operations. LED lighting is installed at the ceilings and 
curtains are used for sheltering from sunlight as well as helping to spread daylight to the clubhouse. Besides, two heating pumps in the indoor swimming pool are installed to regulate both of the water temperature and indoor temperature of the pool. In general, only one heat pump is activated in the swimming in order to save energy. In the purpose of energy saving and maintain energy efficiency, the start time of heating pimp is specially arranged and the indoor air temperature can be adjusted by normal air flow.

"The 7-color recycle bins are put in estate that really alert and encourage residents to participate in daily recycling".

"I appreciate they keep monitoring the start time of heating pimp, energy saving and introducing energy efficient materials such as energy saving LED light bulbs".

\subsection{Green Measures in Estate Restaurant}

Owing to encourage residents to reduce the use of disposables and cultivate good habits of recycle, various practical actions are educated and promoted. No paper cup-the disposable paper cup will not be provided in the Chinese tea corner. Residents are recommended to bring their own water containers. No straw and no plastic tableware posters have been placed. Straw and plastic tableware are not encouraged to use. On-loan services of "Take-away Reusable Lunch Box"residents can borrow a reusable lunch box at the clubhouse for take-away and say "No" to disposable plastic. The excerpts below show the feedback of those practical measures adopted in restaurant of clubhouse.

"I am so proud to see the management taking the lead to protect and promote green living environment, as they have demonstrated a socially responsible company, they are very aware of the daily duties to protect the environment. As such, they are firmly committed to sustainable development and to bring a cleaner environment to our residents, employees and the community in everyday and for long term".

"We appreciate the measures and rationale of green living in clubhouse. So we stop using straw in restaurant. We bring our own bottle for taking water and bring food container to take away food leftover so as to reduce plastic disposables.

\subsection{Estate Green Activities}

Furthermore, education workshops and exhibition display board were displayed in Green Green Club about the awareness of air-quality. Moreover, through organizing different environmental themed workshops, children can learn about environmental awareness and creativity in a funny and creative ways. Most impressive is they organize various interactive, informative and interesting educative environmental activities such as "Environmental Protection Pioneer Campaign", "Environmental Protection Workshop", "Food Waste Composer Visit" have been organized in Park Island from time to time to educate and encourage 
residents to live green. The excerpts below show the positive influences of green management in estate to all those residents.

"I appreciate management have implemented and promoted various environmental measures/activities to reduce disposables and no plastics for protecting environment and reduce wastage. Management takes a good initiative to encourage residents to take part to contribute to protect the earth through their daily operations in restaurant and reading corners".

" $A$ number of environmental facilities were visited such as the food waste decomposer and workshops are arranged to our kids. Our kids and I gained a better understanding of environmental protection and promote green living."

"Environmental protection pioneer workshops and games were organized to educate our kids in their spare time".

Motivating the community to engage voluntarily is the key to success. Small steps and large collection can make a better world for all living creatures. Through sustainability by reducing greenhouse gas emissions, reducing waste products, increasing recycling, etc. both small steps and large collective actions, they showed how such efforts can make a big impact to the community and a better world. Management implements various classes and activities to educate and influence residents to take an active role in responding to environmentally friendly measures.

According to Goldblatt [30], he stated three core green strategies for event organizers: 1) Innovation: creatively harnessing emerging strategies and green technology for increased energy efficiency and environmentalism; 2) Conservation: responsible use of natural resources and waste minimization; and 3) Education: promoting ethical behavior toward energy and the environment while creating memorable event experiences. In Park Island, these three core green event strategies were adopted during Environmental protection activities in Park Island, 1) green technology for increased energy efficiency and environmentalism. Anti-mosquito machines were used in the whole event-mosquito magnets for mosquito control so as to reduce the use of insecticide are used in Park Island. The logic of the anti-mosquito machine is to intimate the release of carbon dioxide from human body to attract mosquitoes in approaching the machines, letting them to air-dried inside the appliance. Since no chemical substance is used in the process of killing mosquitoes, it is both safe and environmentally friendly to use. 2) Various community involvement programs have been organized to encourage community to use natural resources responsibly and waste minimization. For instance, no paper cup and straw will be provided in clubhouse area 3) Environmental protection activities has been organized so as to educate and promote ethical behavior toward energy and the environment while creating memorable and meaningful event experiences.

\subsection{Estate Events}

Management encourages the community to reduce waste at source by donating usable resources to the charities through "Rewarding Recycling Campaign", 
"Green Efforts Give Great Rewards Event", "Environmental Campaign Day", "Green Day Event", Environmental Protection Carnival" and "Second-hand Bazaar", helps to spread the message of fully cherish and utilize materials and adopt a green lifestyle. It raises public awareness of the importance of waste reduction and to encourage the public to make good use of resources, making the world a greener place to live. The excerpts below show the interactive, interesting, influential and inspiring green events for residents.

"The meaningful and inspiring events tailored made were launched for all ages of residents. It nurtures the awareness of environmental preservation and sustainable development for next generation. The objectives of environmental protection activities are for demonstrating environmentally friendly estate management and raise the environmental protection awareness and induce greater community involvement to live green".

The results of in-depth interviews revealed inspiring insights from respondents' perspectives regarding the experiences and benefit contributions of environmental protection activities which were derived the values, attitudes, feelings, intrinsic and extrinsic motivations from respondents through engaging various environmental protection actions to achieve the perceived outcome of sustainability and green globe. Based on the result, environmental protection activities was perceived by all of the study respondents as a fun, educational, influential, informative, interactive and meaningful event. It inspired respondents to embrace positive environmental attitudes and engage in pro-environmental behavior in their daily lives. It raised environmental awareness and moral obligation to engage in environmental protection, induced greater pro-environmental behavior for sustainability. Based on the insights gained from event respondents, lots of contributions are contributed by educative environmental protection activities for nurturing residents to commit in environmental protection, inducing greater pro-environmental behavior for sustainable development.

\section{Conclusions and Recommendations}

This study aimed to investigate various green strategies, measures and activities that have been adopted in a large private residential complex and explore how those strategies has demonstrated extraordinary environmentally friendly estate management that raise the environmental protection awareness for residents to live green in everyday of their lives.

The efforts to combat climate change touch on every part of our lives and should be the responsibilities of all residents, management companies and governments. The issue of climate change can only be sufficiently addressed with wide participation from the governments, different sectors of the businesses and residents. The researchers were delighted to learn that educative environmental protection activities were perceived by all of the study respondents as educative and effective, which demonstrate environmentally friendly estate management and raise the environmental protection awareness and encourage residents' in- 
volvement to live green. The results of this study appear to suggest that all the residents, estate management companies and governments should actively engage in environmental protection for sustainable development.

\subsection{Managerial Implications}

The findings of this study have significant implications for estate management. Based on the results of this research, the following are suggestions to induce greater pro-environmental behavior from event attendees.

\subsection{Recommendations to Estate Management}

- To recycle aluminum cans, glass bottles, and newspapers as well as water. Water recycling is reusing treated wastewater for beneficial purposes such as toilet flushing.

- To make sure recycling bins are enough and clearly marked.

- To estimate and order the right amount of food and beverages for event participants to avoid food wastage.

- To coordinate with environmental promotion organizations to organize more interactive environmental protection activities regularly.

\subsection{Recommendations to Residents}

- Take own bottle and boxes for drinking and take own box to contain take away food.

- To stop using straw while drinking.

- Take bath in less than 10 minutes.

- To participate all the daily environment measures wholeheartedly.

\section{Limitations}

Like all research, this study has a number of limitations which the authors attribute to the relative weakness of interviews to present valid, reliable and trustworthy empirical evidence. Since this study has adopted a qualitative approach, sample size is not a significant issue, despite the small sampling size of interviewees. The focus has been on generating insights on the perceptions of various green measures in clubhouse of Park Island. The research findings should not to be generalized to the population at large since this was never the intention of the researcher. As this study has employed in-depth interviews as the main mode of data collection, the efficiency and effectiveness of this study will depend to some degree on the researcher's ability to assist participants to derive their thoughts, feelings and experiences in their perception of green management in estate. The findings are based on the interviewee's views about how they view the various daily green measures adopted in Park Island. Consequently, it is recognized that the results of this study present a snapshot of thoughts and feelings amongst a specific group of respondents at environmental protection daily measures in Park Island, at a particular point in time. Although 
the authors make no claims regarding the generalization of the results, this study has indicated a concentration of the benefits generated by daily environmental protection measures in Park Island. This finding should be of interest to property management whose is committed to sustainability in daily management.

\section{Conflicts of Interest}

The authors declare no conflicts of interest regarding the publication of this paper.

\section{References}

[1] William, H.H. (2008) Changing Metropolitan America: Planning or a Sustainable Future. Urban Land Institute, Washington DC.

[2] Maser, C.R. and Beaton, S.K. (1998) Setting the Stage for Sustainability. A Citizen's Handbook, Lewis Press.

[3] Chan, S. (2012) A Study on Green Housing Management: How Can Housing Managers' Best Leverage Green Initiatives for Sustainable Development. Thesis. University of Hong Kong, Hong Kong.

[4] Stern, P.C. (2000) New Environmental Theories: Toward a Coherent Theory of Environmentally Significant Behavior. Journal of Social Issues, 56, 407-424. https://doi.org/10.1111/0022-4537.00175

[5] Kollmuss, A. and Agyeman, J. (2002) Mind the Gap: Why Do People Act Environmentally and What Are the Barriers to Pro-Environmental Behavior? Environmental Education Research, 8, 239-260.

[6] Kraft, P., Rise, J., Sutton, S. and Røysamb, E. (2005) Perceived Difficulty in the Theory of Planned Behaviour: Perceived Behavioural Control or Affective Attitude? British Journal of Social Psychology, 44, 479-496. https://doi.org/10.1348/014466604X17533

[7] Laroche, M., Bergeron, J. and Barbaro-Forleo, G. (2001) Targeting Consumers Who Are Willing to Pay More for Environmentally Friendly Products. Journal of Consumer Marketing, 18, 503-520. https://doi.org/10.1108/EUM0000000006155

[8] WCED (1987) World Commission on Environment and Development. Our Common Future. Oxford University Press, Oxford.

[9] Blewitt, J. (2012) Understanding Sustainable Development. Routledge.

[10] United Nations Secretary and General's High-Level Panel (2012) Global Sustainability. Resilient People, Resilient Planet: A Future Worth Choosing. United Nations, New York.

[11] Lambin, E.F. (2005) Conditions for Sustainability of Human-Environment Systems: Information, Motivation, and Capacity. Global Environmental Change, 15, 177-180. https://doi.org/10.1016/j.gloenvcha.2005.06.002

[12] Brinsmead, T.S. and Hooker, C. (2011) Complex Systems Dynamics and Sustainability: Conception, Method and Policy. In: Hooker, C., Ed., Handbook of the Philosophy of Science, North-Holland/Elsevier, Amsterdam, 809-838. https://doi.org/10.1016/B978-0-444-52076-0.50026-2

[13] Moldan, B., et al. (2012) How to Understand and Measure Environmental Sustainability: Indicators and Targets. Ecological Indicators, 17, 4-13. https://doi.org/10.1016/j.ecolind.2011.04.033

[14] Hove, H. (2004) Critiquing Sustainable Development: A Meaningful Way of Me- 
diating the Development Impasse? Undercurrent, 1.

[15] Prughm, T. and Assadourian, E. (2003) What Is Sustainability, Anyway? World Watch, 16, 10.

[16] Stiglitz, J.E., Sen, A. and Fitoussi, J.P. (2009) Report by the Commission on the Measurement of Economic Performance and Social Progress.

[17] Brandon, P.S. and Lombardi, P. (2011) Evaluating Sustainable Development in the Built Environment. Wiley-Blackwell, Chichester, Ames.

[18] Laing, J. and Frost, W. (2010) How Green Was My Festival: Exploring Challenges and Opportunities Associated with Staging Green Activities. International Journal of Hospitality Management, 29, 261-267. https://doi.org/10.1016/j.ijhm.2009.10.009

[19] Swarbrooke, J. (1999) Sustainable Tourism Management. Cabi, New York. https://doi.org/10.1079/9780851993140.0000

[20] Ahmad, N.L., Rashid, W.E.W., Razak, N.A., Yusof, A.N.M. and Shah, N.S.M. (2013) Green Event Management and Initiatives for Sustainable Business Growth. International Journal of Trade, Economics and Finance, 4, 331. https://doi.org/10.7763/IJTEF.2013.V4.311

[21] Eckerstein, A. (2002) Evaluation of Event Marketing. International Management Master Thesis, Vol. 25, Goteborg University.

[22] Berridge, G. (2007) Activities Design and Experience. Activities Management Series, Elsevier, Amsterdam.

[23] Silversm, J.R. (2004) Professional Event Coordination. John Wiley \& Sons Inc., Hoboken.

[24] Green, G.H. and Haines, A. (2008) Asset Building \& Community Development. Sage Publications, Los Angeles.

[25] Yin, R.K. (1994) Case Study Research: Design and Methods. 2nd Edition, Sage, Thousand Oaks.

[26] Gordon, W. and Langmaid, R. (1998) Qualitative Market Research: A Practitioner's and Buyer's Guide. Gower, Aldershot.

[27] Holloway, I., Brown, L. and Shipway, R. (2007) Meaning Not Measurement: Using Ethnography to Bring a Deeper Understanding to the Participant Experience of Festivals and Activities. International Journal of Event and Festival Management, 1, 74-85. https://doi.org/10.1108/17852951011029315

[28] Veal, A.J. (1994) Research Methods for Leisure and Tourism: A Practical Guide. 3rd Edition, Pearson Education, Harlow.

[29] Myers, M. (2013) Qualitative Research in Business \& Management. 2nd Edition, Sage Publications, London.

[30] Goldblatt, S. (2011) The Complete Guide to Greener Meetings and Activities. John Wiley \& Sons, Inc., Hoboken. 